\title{
ERRATUM
}

\section{Haloanaerobium lacusroseus sp. nov., an Extremely Halophilic Fermentative Bacterium from the Sediments of a Hypersaline Lake}

J.-L. CAYOL, B. OLLIVIER, B. K. C. PATEL, E. AGERON, P. A. D. GRIMONT, G. PRENSIER, AND J.-L. GARCIA

Laboratoire de Microbiologie ORSTOM, Université de Provence, 13331 Marseille Cedex 3, Unité des Entérobactéries, INSERM U199, Institut Pasteur, 75724 Paris Cedex 15, and Laboratoire de Microbiologie, Université Blaise Pascal, 63177 Aubière Cedex,

France, and Faculty of Science and Technology, Griffith University, Brisbane, Queensland 4111, Australia

Volume 45, no. 4, p. 791, column 2, line 33: "number L39767" should read "number L39787." 